\title{
KETEPATAN PEMORSIAN SAYUR TERHADAP STANDAR PORSI MAKANAN BIASA
}

\author{
Sabrina Apriliani ${ }^{{ }^{*}}$, Luh Suranadi ${ }^{1}$, Susilo Wirawan ${ }^{1}$ dan AASP Chandradewi \\ ${ }^{1}$ Jurusan Gizi, Poltekkes Kemenkes Mataram, Indonesia \\ Jalan Praburangkasari Dasan Cermen, Sandubaya Kota Mataram \\ Telp./Fax. (0370) 633837, \\ Email : Sabrina.apriliani23@gmail.com
}

\begin{tabular}{l}
\hline \hline Article Info \\
\hline Article history: \\
Received July $16^{\text {th }}, 2019$ \\
Revised August $25^{\text {th }}, 2019$ \\
Accepted September $27^{\text {th }}, 2019$
\end{tabular}

Keyword:

Large Portion; Portion accuracy; Standard servings

\begin{abstract}
Background. Consumption of vegetables and fruit body needs for vitamins, minerals and fiber in achieving a healthy diet as recommended by guidelines of balanced nutrition for optimal health. Most vitamins and minerals found in fruits and vegetables has a function as an antioxidant that may reduce the incidence of noncommunicable diseases related to nutrition, as a result of the excess or deficiency. Large portions often becomes very important when serving food, especially in the food pemortion advantages and disadvantages still occur because no portion of the right size in pemortion food. Pemortion these foods should be according to the standard portion that has been set by the installation of a hospital nutrition. Huge portions, will directly influence the nutrients contained in a food. Purpose Knowing picture vegetable pemortion accuracy of the standards usual food servings at lunch in Tabanan Hospital.
\end{abstract}

Research Methods. This research is an observational study. The study was conducted on 22 to 30 March 2019 in BRSUD Tabanan. The data were taken using accidental sampling method. Samples taken care third grade.

Research Result. Large servings of vegetables at lunch for ordinary food in hospitals Tabanan as follows: vegetable tamarind 160.7 grams, vegetable nodes 175 grams, vegetable ointment 170.4 grams, vegetable bobor 131.8 grams, vegetables, tamarind 177 grams, vegetable soup 104.5 grams, vegetable lodeh 102.6 grams and 71.4 grams of vegetable ointment. Power pemortion obtained are four power pemortion with vocational education and universities.

Conclusion. Great accuracy servings of vegetables served by 4 workers pemortion average is not appropriate because more than a standard portion

Copyright $\odot$ Jurnal Gizi Prima All rights reserved.

\section{PENDAHULUAN}

Konsumsi sayur dan buah diperlukan tubuh sebagai sumber vitamin, mineral dan serat dalam mencapai pola makan sehat sesuai anjuran pedoman gizi seimbang untuk kesehatan yang optimal. Sebagian vitamin dan mineral yang terdapat dalam sayur dan buah mempunyai fungsi sebagai antioksidan sehingga dapat mengurangi kejadian penyakit tidak menular terkait gizi, sebagai dampak dari kelebihan atau kekurangan gizi (Hermina dan S Prihatini, 2014).

Berdasarkan hasil penelitian Ida Ayu Eka Astuti tahun 2018 diinstalasi gizi RSU Bahtermas ketepatan standar porsi sayuran yang dikategorikan $100 \%$ kurang. Angka ini menjadi ketidaktepatan besar porsi makan. Rata-rata besar porsi sayuran yang disajikan pada kelas perawatan III adalah sebesar 52.08 gram. Standar 
porsi sayuran yang ditetapkan untuk kelas perawatan III sebesar 150 gram/hari untuk 3 kali makan. Serta hasil dari penelitian Rina Ambarwati pada tahun 2016 di instalasi gizi RSUD Panembahan Senopati Bantul menunjukkan ketepatan sayur antara besar porsi yang direncanakan dan disajikan adalah 66,7 \% tepat dan 33,7 tidak tepat. Pemorsian sayur menurut standar yaitu 100 gram.

Besar porsi seringkali menjadi hal yang sangat penting saat menyajikan makanan, terutama dalam pemorsian makanan masih terjadi kelebihan dan kekurangan porsi karena tidak ada ukuran yang tepat dalam pemorsian makanan. Pemorsian makanan ini harus sesuai dengan standar porsi yang telah di tentukan oleh pihak instalasi gizi rumah sakit. Besar porsi akan berpengaruh langsung terhadap zat gizi yang terkandung dalam suatu makanan. (Lutfiana, fitria, 2016).

Menurut Astrini Retno 2017 yang melakukan penelitian di Rumah Sakit PKU Muhammadiyah Bantul tentang hubungan karakteristik tenaga pemorsi dan alat pemorsi dengan ketepatan pemorsian makanan berdasarkan standar porsi menyatakan bahwa ketetapan berat porsi yang disajikan sangat dipengaruhi dari tenaga pemorsi yang melakukan pemorsian serta alat yang digunakan untuk pemorsian. Dalam penelitian ini, peneliti ingin melakukan penelitian di RSUD Tabanan mengenai ketepatan pemorsian sayur terhadap standar porsi sayur makanan biasa pada makan siang di RSUD Tabanan.

Tujuan dari penelitian ini adalah Mengetahui gambaran ketepatan pemorsian sayur terhadap standar porsi makanan biasa pada makan siang di RSUD Tabanan.

\section{METODE PENELITIAN}

Penelitian ini menggunakan observasi yang bersifat deskriptif, obyek dalam penelitian adalah hidangan sayur pada menu makan siang untuk makanan biasa, data diambil menggunakan metode aksidental sampling dimana pengambilan sampel tidak ditetapkan lebih dahulu, peneliti langsung saja mengumpulkan data dari unit sampling yang ditemui. Sampel diambil di perawatan kelas III.

Data tentang hidangan sayur pada menu makan siang untuk makanan biasa, yang dikumpulkan dengan cara food weighing dengan mengunakan alat bantu timbangan dengan kapasitas $10 \mathrm{~kg}$ dengan tingkat ketelitian 1 gram.

Tenaga pemorsi meliputi jenis kelamin dan pendidikan diolah dalam tabel distribusi frekuensi dan disajikan secara deskriptif yaitu, dengan klasifikasi menjadi : Jenis kelamin, di kelompokkan menjadi 2 yaitu :Laki-laki dan Perempuan, Tingkat pendidikan berdasarkan Depdiknas RI 2003, dikelompokkan berdasarkan kategori : Dasar (Tidak sekolah dan SD), Menengah (SMP, SMA/SMK), Tinggi (Perguruan TInggi). Lama bekerja, dikelompokkan menjadi 2 yaitu : Lama $: \geq 10$ tahun, Baru $:<10$ tahun.

\section{HASIL PENELITIAN}

\section{Standar porsi sayur di BRSUD Tabanan}

Standar porsi sayur makanan biasa untuk semua kelas perawatan di BRSUD Tabanan untuk satu hari memiliki porsi yang berbeda, untuk makan pagi sayur yang dihidangkan sebesar 50 gram, makan siang dan makan malam sebesar 75 gram.

\section{Berat Porsi Sayur Di Instalasi Gizi (hari I)}

Pada hari pertama pengamatan yang dilakukan yaitu hidangan sayur pada makan siang untuk makanan biasa memperoleh 9 objek yang berada di perawatan kelas III. Adapun berat sayur yang disajikan oleh tenaga pemorsi sebagai berikut : 
Tabel 1. Berat Porsi Hidangan Sayur Pada Makan Siang Untuk Makanan Biasa Yang Berupa Sayur Asem di RSUD Tabanan

\begin{tabular}{|c|c|c|c|}
\hline Obyek & $\begin{array}{c}\text { Berat Porsi Sayuran } \\
\text { Asem (gram) }\end{array}$ & Berat Matang (gram) & $\begin{array}{c}\text { Ketepatan Porsi } \\
\text { Sayur }\end{array}$ \\
\hline 1 & & 122 & Tidak tepat Tepat \\
\hline 2 & & 159 & Tidak Tepat \\
\hline 3 & & 170 & Tidak tepat \\
\hline 4 & & 143 & Tidak Tepat \\
\hline 5 & & 164 & Tidak Tepat \\
\hline 6 & 100 & 173 & Tidak tepat \\
\hline 7 & & 150 & Tidak tepat \\
\hline 8 & & 175 & Tidak Tepat \\
\hline 9 & & 191 & Tidak Tepat \\
\hline Rata-rata & & 160,7 & Tidak tepat \\
\hline Persentase & 100 & $160,7 \%$ & Tidak tepat \\
\hline
\end{tabular}

Berdasarkan hasil pengamatan dan penimbangan pada hari pertama pemorsian sayur asem yang diporsikan oleh tanaga pemorsi Gusti Ayu Putu Budyawati dengan lama bekerja 4 tahun menunjukan bahwa masih ada berat porsi yang tidak tepat porsi terhadap standar porsi yang telah ditetapkan di instalasi gizi. Persentase ketepatan porsi terdapat pemorsian yang tidak tepat sebesar $160,7 \%$ memiliki selisi lebih $60,7 \%$. Pada saat penelitian standar porsi sayur yang menggunakan kuah 100 gram.

\section{Berat Porsi Sayur Di Instalasi Gizi (hari II)}

Pada hari kedua pengamatan yang dilakukan yaitu hidangan sayur pada makan siang untuk makanan biasa memperoleh 7 objek yang berada di perawatan kelas III. Adapun berat sayur yang disajikan oleh tenaga pemorsi sebagai berikut:

Tabel 2. Berat Porsi Hidangan Sayur Pada Makan Siang Untuk Makanan Biasa Yang Berupa Sayur Bening di RSUD Tabanan

\begin{tabular}{|c|c|c|c|}
\hline Obyek & $\begin{array}{c}\text { Batas normal porsi } \\
\text { (gram) }\end{array}$ & Berat Matang (gram) & $\begin{array}{c}\text { Ketepatan Porsi } \\
\text { Sayur }\end{array}$ \\
\hline 1 & & 169 & Tidak tepat \\
\hline 2 & & 220 & Tidak tepat \\
\hline 3 & & 110 & Tidak tepat \\
\hline 4 & & 181 & Tidak Tepat \\
\hline 5 & & 196 & Tidak tepat \\
\hline 6 & 100 & 185 & Tidak tepat \\
\hline 7 & & 164 & Tidak tepat \\
\hline 8 & & 175 & Tidak tepat \\
\hline 9 & & $175 \%$ & Tidak tepat \\
\hline Rata-rata & & 169 & Tidak tepat \\
\hline Persentase & 100 & 220 & Tidak tepat \\
\hline
\end{tabular}

Berdasarkan hasil pengamatan dan penimbangan pada hari kedua pemorsian sayur bening yang diporsikan oleh tanaga pemorsi Gusti Ayu Putu Budyawati dengan lama bekerja 4 tahun menunjukan bahwa berat porsi yang tidak tepat terhadap standar porsi yang telah ditetapkan di instalasi gizi. Persentase ketepatan porsi terdapat pemorsian yang tidak tepat sebesar $175 \%$ memiliki selisi lebih $75 \%$. Pada saat penelitian standar porsi sayur yang menggunakan kuah 100 gram.

\section{Berat Porsi Sayur Di Instalasi Gizi (hari III)}

Pada hari ketiga pengamatan yang dilakukan yaitu hidangan sayur pada makan siang untuk makanan biasa memperoleh 12 objek yang berada di perawatan kelas III. Adapun berat sayur yang disajikan oleh tenaga pemorsi sebagai berikut : 
Tabel 3. Berat Porsi Hidangan Sayur Pada Makan Siang Untuk Makanan Biasa Yang Berupa Sayur Urap di RSUD Tabanan

\begin{tabular}{|c|c|c|c|}
\hline Obyek & $\begin{array}{c}\text { Batas normal porsi } \\
\text { (gram) }\end{array}$ & Berat Matang (gram) & $\begin{array}{c}\text { Ketepatan Porsi } \\
\text { Sayur }\end{array}$ \\
\hline 1 & & 132 & Tidak tepat \\
\hline 2 & & 115 & Tidak Tepat \\
\hline 3 & & 124 & Tidak tepat \\
\hline 4 & & 120 & Tidak Tepat \\
\hline 5 & & 127 & Tidak Tepat \\
\hline 6 & & 122 & Tidak tepat \\
\hline 7 & 75 & 127 & Tidak tepat \\
\hline 8 & & 118 & Tidak Tepat \\
\hline 9 & & 126 & Tidak Tepat \\
\hline 10 & & 159 & Tidak tepat \\
\hline 11 & & 125 & Tidak tepat \\
\hline 12 & & 139 & Tidak tepat \\
\hline Rata-rata & & 170.4 & Tidak tepat \\
\hline Persentase & 100 & $170,4 \%$ & Tidak tepat \\
\hline
\end{tabular}

Berdasarkan hasil pengamatan dan penimbangan pada hari ketiga pemorsian sayur asem yang diporsikan oleh tanaga pemorsi G.A Km. Sri Wirastini dengan lama bekerja 12 tahun menunjukan bahwa berat porsi yang tidak tepat terhadap standar porsi yang telah ditetapkan di instalasi gizi. Persentase ketepatan porsi terdapat pemorsian yang tidak tepat sebesar $170.4 \%$ memiliki selisi lebih $70.4 \%$. Pada saat penelitian standar porsi sayur yang tanpa kuah 75 gram

\section{Berat Porsi Sayur Di Instalasi Gizi (hari IV)}

Pada hari keempat pengamatan yang dilakukan yaitu hidangan sayur pada makan siang untuk makanan biasa memperoleh 10 objek yang berada di perawatan kelas III. Adapun berat sayur yang disajikan oleh tenaga pemorsi sebagai berikut:

Tabel 4. Berat Porsi Hidangan Sayur Pada Makan Siang Untuk Makanan Biasa Yang Berupa Sayur Bobor di RSUD Tabanan

\begin{tabular}{|c|c|c|c|}
\hline Obyek & $\begin{array}{c}\text { Batas normal porsi } \\
\text { (gram) }\end{array}$ & Berat Matang (gram) & $\begin{array}{c}\text { Ketepatan Porsi } \\
\text { Sayur }\end{array}$ \\
\hline 1 & & 111 & Tidak Tepat \\
\hline 2 & & 150 & Tidak Tepat \\
\hline 3 & & 148 & Tidak tepat \\
\hline 4 & & 112 & Tidak Tepat \\
\hline 5 & & 140 & Tidak Tepat \\
\hline 6 & 100 & 124 & Tidak tepat \\
\hline 7 & & 112 & Tidak tepat \\
\hline 8 & & 178 & Tidak Tepat \\
\hline 9 & & 112 & Tidak Tepat \\
\hline 10 & & 131 & Tidak tepat \\
\hline Rata-rata & & 131.8 & Tidak tepat \\
\hline Persentase & 100 & $131.8 \%$ & Tidak tepat \\
\hline
\end{tabular}

Berdasarkan hasil pengamatan dan penimbangan pada hari keempat pemorsian sayur asem yang diporsikan oleh tanaga pemorsi G.A Km. Sri Wirastini dengan lama bekerja 12 tahun menunjukan bahwa berat porsi yang tidak tepat terhadap standar porsi yang telah ditetapkan di instalasi gizi. Persentase ketepatan porsi terdapat pemorsian yang tidak tepat sebesar $131.8 \%$ memiliki selisi lebih $31.8 \%$. Pada saat penelitian standar porsi sayur yang menggunakan kuah 100 gram. 
Berat Porsi Sayur Di Instalasi Gizi (hari V)

Pada hari kelima pengamatan yang dilakukan yaitu hidangan sayur pada makan siang untuk makanan biasa memperoleh 12 objek yang berada di perawatan kelas III. Adapun berat sayur yang disajikan oleh tenaga pemorsi sebagai berikut:

Tabel 5. Berat Porsi Hidangan Sayur Pada Makan Siang Untuk Makanan Biasa Yang Berupa Sayur Asem di RSUD Tabanan

\begin{tabular}{|c|c|c|c|}
\hline Obyek & $\begin{array}{c}\text { Batas normal porsi } \\
\text { (gram) }\end{array}$ & Berat Matang (gram) & $\begin{array}{c}\text { Ketepatan Porsi } \\
\text { Sayur }\end{array}$ \\
\hline 1 & & 171 & Tidak Tepat \\
\hline 2 & & 165 & Tidak Tepat \\
\hline 3 & & 176 & Tidak Tepat \\
\hline 4 & & 178 & Tidak Tepat \\
\hline 5 & & 171 & Tidak Tepat \\
\hline 6 & & 164 & Tidak tepat \\
\hline 7 & 100 & 186 & Tidak tepat \\
\hline 8 & & 202 & Tidak Tepat \\
\hline 9 & & 176 & Tidak Tepat \\
\hline 10 & & 191 & Tidak tepat \\
\hline 11 & & 184 & Tidak Tepat \\
\hline 12 & & 164 & Tidak Tepat \\
\hline Rata-rata & & 177 & Tidak tepat \\
\hline Persentase & 100 & $177 \%$ & Tidak tepat \\
\hline
\end{tabular}

Berdasarkan hasil pengamatan dan penimbangan pada hari kelima pemorsian sayur asem yang diporsikan oleh tanaga pemorsi Luh Gede Puriasih dengan lama bekerja 12 tahun menunjukan bahwa berat porsi yang tidak tepat terhadap standar porsi yang telah ditetapkan di instalasi gizi. Persentase ketepatan porsi terdapat pemorsian yang tidak tepat sebesar $177 \%$ memiliki selisi lebih $77 \%$. Pada saat penelitian standar porsi sayur yang menggunakan kuah 100 gram.

\section{Berat Porsi Sayur Di Instalasi Gizi (hari VI)}

Pada hari keenam pengamatan yang dilakukan yaitu hidangan sayur pada makan siang untuk makanan biasa memperoleh 15 objek yang berada di perawatan kelas III. Adapun berat sayur yang disajikan oleh tenaga pemorsi sebagai berikut: 
Tabel 6. Berat Porsi Hidangan Sayur Pada Makan Siang Untuk Makanan Biasa Yang Berupa Sayur Sop di RSUD Tabanan

\begin{tabular}{|c|c|c|c|}
\hline Obyek & $\begin{array}{c}\text { Batas normal porsi } \\
\text { (gram) }\end{array}$ & Berat Matang (gram) & $\begin{array}{c}\text { Ketepatan Porsi } \\
\text { Sayur }\end{array}$ \\
\hline 1 & & 81 & Tidak Tepat \\
\hline 2 & & 122 & Tidak Tepat \\
\hline 3 & & 79 & Tidak tepat \\
\hline 4 & & 83 & Tidak Tepat \\
\hline 5 & & 78 & Tidak Tepat \\
\hline 6 & & 97 & Tidak tepat \\
\hline 7 & & 98 & Tidak tepat \\
\hline 8 & & 122 & Tidak Tepat \\
\hline 9 & 100 & 104 & Tidak Tepat \\
\hline 10 & & 86 & Tidak tepat \\
\hline 11 & & 134 & Tidak tepat \\
\hline 12 & & 97 & Tidak tepat \\
\hline 13 & & 129 & Tidak tepat \\
\hline 14 & & 120 & Tidak tepat \\
\hline 15 & & 138 & Tidak tepat \\
\hline Rata-rata & & 104.5 & Tidak tepat \\
\hline Persentase & 100 & $104.5 \%$ & Tidak tepat \\
\hline
\end{tabular}

Berdasarkan hasil pengamatan dan penimbangan pada hari kelima pemorsian sayur sop yang diporsikan oleh tanaga pemorsi Luh Gede Puriasih dengan lama bekerja 12 tahun menunjukan bahwa berat porsi yang tidak tepat terhadap standar porsi yang telah ditetapkan di instalasi gizi. Persentase ketepatan porsi terdapat pemorsian yang tidak tepat sebesar $104.5 \%$ memiliki selisi lebih $4.5 \%$. Pada saat penelitian standar porsi sayur yang menggunakan kuah 100 gram.

\section{Berat Porsi Sayur Di Instalasi Gizi (hari VII)}

Pada hari ketujuh pengamatan yang dilakukan yaitu hidangan sayur pada makan siang untuk makanan biasa memperoleh 12 objek yang berada di perawatan kelas III. Adapun berat sayur yang disajikan oleh tenaga pemorsi sebagai berikut:

Tabel 7. Berat Porsi Hidangan Sayur Pada Makan Siang Untuk Makanan Biasa Yang Berupa Sayur Lodeh di RSUD Tabanan

\begin{tabular}{|c|c|c|c|}
\hline Obyek & $\begin{array}{c}\text { Batas normal porsi } \\
\text { (gram) }\end{array}$ & Berat Matang (gram) & $\begin{array}{c}\text { Ketepatan Porsi } \\
\text { Sayur }\end{array}$ \\
\hline 1 & & 140 & Tidak Tepat \\
\hline 2 & & 87 & Tidak Tepat \\
\hline 3 & & 84 & Tidak tepat \\
\hline 4 & & 110 & Tidak Tepat \\
\hline 5 & & 131 & Tidak Tepat \\
\hline 6 & & 103 & Tidak tepat \\
\hline 7 & 100 & 117 & Tidak Tepat \\
\hline 8 & & 85 & Tidak Tepat \\
\hline 9 & & 105 & Tidak Tepat \\
\hline 10 & & 85 & Tidak tepat \\
\hline 11 & & 93 & Tidak tepat \\
\hline 12 & & 92 & Tidak tepat \\
\hline Rata-rata & & 102.6 & Tidak tepat \\
\hline Persentase & 100 & $102.6 \%$ & Tidak tepat \\
\hline
\end{tabular}

Berdasarkan hasil pengamatan dan penimbangan pada hari kelima pemorsian sayur lodeh yang diporsikan oleh tanaga pemorsi Ni wayan Ernawati dengan lama bekerja 14 tahun menunjukan bahwa berat porsi yang tidak tepat terhadap standar porsi yang telah ditetapkan di instalasi gizi. Persentase ketepatan porsi terdapat 
pemorsian yang tidak tepat sebesar $102.6 \%$ memiliki selisi lebih $2.6 \%$. Pada saat penelitian standar porsi sayur yang menggunakan kuah 100 gram.

\section{Berat Porsi Sayur Di Instalasi Gizi (hari VIII)}

Pada hari kedelapan pengamatan yang dilakukan yaitu hidangan sayur pada makan siang untuk makanan biasa memperoleh 10 objek yang berada di perawatan kelas III. Adapun berat sayur yang disajikan oleh tenaga pemorsi sebagai berikut :

Tabel 8. Berat Porsi Hidangan Sayur Pada Makan Siang Untuk Makanan Biasa Yang Berupa Sayur Lodeh di RSUD Tabanan

\begin{tabular}{cccc}
\hline Obyek & $\begin{array}{c}\text { Batas normal porsi } \\
\text { (gram) }\end{array}$ & Berat Matang (gram) & $\begin{array}{c}\text { Ketepatan Porsi } \\
\text { Sayur }\end{array}$ \\
\hline 1 & & 55 & Tidak Tepat \\
2 & & 66 & Tidak Tepat \\
3 & & 65 & Tidak tepat \\
4 & 75 & 98 & Tidak Tepat \\
5 & & 99 & Tidak Tepat \\
6 & & 55 & Tidak tepat \\
7 & & 70 & Tidak Tepat \\
8 & & 59 & Tidak Tepat \\
9 & & 69 & Tidak Tepat \\
10 & & 78 & Tidak Tepat \\
\hline Rata-rata & & 71.4 & Tidak tepat \\
\hline Persentase & 100 & $95.2 \%$ & Tidak tepat \\
\hline
\end{tabular}

Berdasarkan hasil pengamatan dan penimbangan pada hari kelima pemorsian sayur lodeh yang diporsikan oleh tanaga pemorsi Ni wayan Ernawati dengan lama bekerja 14 tahun menunjukan bahwa berat porsi yang tidak tepat terhadap standar porsi yang telah ditetapkan di instalasi gizi. Persentase ketepatan porsi terdapat pemorsian yang tidak tepat sebesar $95.2 \%$ memiliki selisi kurang $4.8 \%$. Pada saat penelitian standar porsi sayur yang menggunakan kuah 75 gram.

\section{PEMBAHASAN}

Menurut Wijayanti (2008) porsi makanan adalah besarnya porsi bahan makanan per sajian pada setiap kali makan. Berdasarkan hasil penelitian menujukan bahwa sebagian besar hasil pemorsian dari pemorsian sayur asem, sayur bening, sayur urap, sayur bobor, sayur sop dan sayur lodeh yang disajikan tidak tepat porsi, porsi yang disajikan tidak tepat sebanyak $160.7 \%$ dan $177 \%$ sayur asem , $175 \%$ sayur bening , $170.4 \%$ dan $95.2 \%$ sayur urap , $131.8 \%$ sayur bobor, 104.5\% sayur sop, 102,6\% sayur lodeh. Rata-rata berat porsi sayurn yang disajikan pada kelas perawatan III untuk sayur asem hari pertama sebesar 106.7 gram, sayur bening 175 gram, sayur urap hari ketiga sebesar 170.4 gram, sayur bobor 131.8 gram, sayur asem hari kelima sebesar 177 gram, sayur sop sebesar 104.5 gram, sayur lodeh sebesar 102.6 gram dan sayur urap hari kedelapan sebesar 71.4 gram.

Sejalan dengan penelitian (Harnack, 2004) kesulitan terbesar dalam menetapkan porsi makanan disebabkan oleh perbedaan antara ukuran presepsi individu dan sarana alat bantu estimasi porsi makanan yang biasa digunakan individu dalam menetapkan porsi makanan. Porsi yang lebih besar akan menyebabkan kandungan gizi makanan meningkat begitu juga sebaliknya porsi yang lebih kecil akan menyebabkan kandungan gizi makanan berkurang.

Berdasarkan hasil penelitian, 4 tenaga pemorsi yang memorsikan sayur selama 8 hari pengamatan memiliki tingkat pendidikan dalam kategori menengah dan tinggi, akan tetapi rata-rata porsi sayur yanh dihasilkan tidak tepat karena lebih dan kurang dari standar porsi yang telah ditetapkan. Hal ini disebabkan karena kemampuan setiap tenaga pemorsi berbeda-beda ddalam memorsikan makanan dan tidak ada pelatihan untuk tenaga pemorsi dalam hal pemorsian makanan sehingga perlu adanya pelatihan atau edukasi seara berkala mengenai pemorsian agar tenaga pemorsi terampil dalam memorsikan makanan. 
Selain pendidikan, lamanya bekrja juga dapat mempengaruhi ketepatan porsi sayur disebabkan oleh pengalaman tenaga pemorsi dalam melakukan pemorsian makanan. Tenaga kerja yang masa kerjanya lebih lama seharusnya dapat melakukan pemorsian dengan tepat karena lebih berpengalaman dalam kegiatan pemorsian dibandingkan dengan tenaga kerja yang masih baru.

Bedasarkan hasil penelitian, dari 4 tenaga pemorsi, terdapat tenaga pemorsi yang dikategorikan masih baru yaitu tenaga pemorsi Gusti Ayu Putu Buyawati dengan lama bekerja 4 tahun, persentase ketidaktepatan porsi sayur sebanyak $60.7 \%$ untuk sayur asem dan $75 \%$ untuk sayur bening, sedangakan tenaga pemorsi yang dikategorikan lama yaitu tenaga pemorsi Ni Wayan Ernawati dengan lama bekerja 14 tahun, persentase ketidak tepatan porsi sayur sebanyak $2.6 \%$ untuk sayur lodeh dan $4.8 \%$ untuk sayur urap. Hal ini menunjukkan bahwa, keberhasilan dalam memrsikan sayur tidak hanya dipengaruhi pendidikan tetapi juga dipengaruhi oleh lama bekerja.

\section{KESIMPULAN}

Standar porsi hidangan sayuran pada makan siang untuk makanan biasa di RSUD Tabanan yaitu 75 gram.Besar porsi hidangan sayuran pada makan siang untuk makanan biasa di RSUD Tabanan sebagai berikut : sayur asem 160.7 gram, sayur bening 175 gram, sayur urap 170.4 gram, sayur bobor 131.8 gram, sayur asem 177 gram, sayur sop 104.5 gram, sayur lodeh 102.6 gram dan sayur urap 71.4 gram.Ketidaktepatan standar porsi hidangan sayuran pada makan siang untuk makanan biasa di RSUD Tabanan yaitu sayur asem $60.7 \%$, sayur bening $75 \%$, sayur urap $70.4 \%$, sayur bobor $31.8 \%$, sayur asem $77 \%$, sayur sop $4.5 \%$, sayur lodeh $2.6 \%$ dan sayur urap $4.8 \%$.

\section{SARAN}

Sebaiknya tenaga pemorsi saat menyajikan makanan untuk pasien mengikuti standar porsi makanan yang di tetapkan oleh RSUD Tabanan agar besar porsi hidangan sayur tepat dengan standar porsi yang ditetapkan dan memberikan edukasi kepada petugas pemorsian tentang pentingnya memperhatikan standar porsi yang telah ditetapkan

\section{DAFTAR PUSTAKA}

Ambarwati, R. (2017). Hubungan ketepatan waktu penyajian dan mutu makanan dengan sisa makanan pasien dewasa non diet di Rsu Pku Muhammadiyah Bantul.

Ambarwati, R. (2017). Laporan Praktik Kuliah Lapangan (PKL) Menetapkan Standar RS Dan Perhitungan Kebutuhan Bahan Makanan

Aritonang, Irianton \& Endah Priharsiwi, 2009. Menajeman Penyelenggaraan Makanan \& Asuhan Gizi. Yogyakarta : Lautika.

Astuti Eka. (2018). Gambaran Kesesuaian standar Porsi Makanan Rumah Sakit Dengan Besar Porsi Yang Disajikan Di Instalasi Gizi RSUD Bahteramas Kota Kendari Chasanah, Uswatun. 2018. "HUBUNGAN PENDIDIKAN , LAMA BEKERJA DAN PENJAMAH
MAKANAN DENGAN KETEPATAN."

Dewi. (2014). Tinjauan Pustaka Pengertian Buah dan Sayuran, Hal 6-34.

Kemenkes Nomor : 1333/Menkes/Sk/XII/1999 tentang Pelayanan Gizi Rumah Sakit (PGRS).

Kemenkes RI . 2013 Pedoman Pelayanan Gizi Rumah Sakit Jakarta

Moehyi Sjahmien. 1997. Pengaturan makanan dan diit yntuk penyembuhan penyakit. Jakarta : PT Gramedia Pustaka Utama.

Moehyi Sjahmien. 1992. Penyelenggaraan makanan institusi dan Jasaboga. Jakarta: Bharata. Moehyi Sjahmien. 1997. Pengaturan makanan dan diit yntuk penyembuhan penyakit. Jakarta : PT Gramedia Pustaka Utama. 
Pangan, M. G., Rochimiwati, S. N., Arifin, N. A., Gizi, J., Kemenkes, P. K., Gizi, A. J., \& Kemenkes, P. K. (2014). ANALISIS MENU MAKANAN BIASA KELAS III, XVII.

Publikasi, N., Wadyomukti, R. A., Gizi, P. D. I. V, Gizi, J., Kesehatan, P., \& Kesehatan, K. (2017). Hubungan Karakteristik Tenaga Pemorsi dan Alat Pemorsian Dengan Ketepatan Pemorsian Makanan Pokok Berdasarkan Standar Porsi di Rumah Sakit PKU Muhammadiyah Bantul. Jiournal of The British Dietetic Association, 46-62.

Ratna, M. R. (2009). EVALUASI MANAJEMEN PENYELENGGARAAN MAKANAN INSTITUSI DI RUMAH SAKIT ORTOPEDI Prof. Dr. R. SOEHARSO SURAKARTA. Karya Tulis Ilmiah.

Ronitawati, P. (2016). Analisis model sistem penyelenggaraan makanan dan kualitas menu makan siang di sekolah dasar putri ronitawati. Skripsi.

Umihani, A., \& Pramono, A. (2015). Analisis Biaya Yang Hilang Dari Sisa Makanan Pasien Di Rsud Dr. Adhyatma, Mph. Journal of Nutrition College, 4, 18-23. Diambil dari http://ejournals1.undip.ac.id/index.php/jnc 